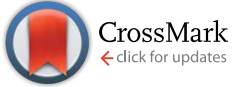

Cite this: RSC Adv., 2017, 7, 8077

Received 4th December 2016 Accepted 17th January 2017

DOI: $10.1039 / c 6 r a 27749 g$

www.rsc.org/advances

\section{Photoinduced structural changes of cationic azo dyes confined in a two dimensional nanospace by two different mechanisms $\uparrow$}

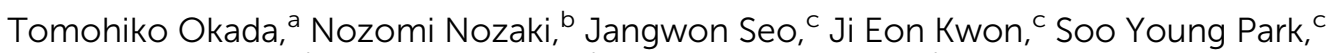 \\ Hideo Hashizume, ${ }^{\text {d }}$ Takayoshi Sasaki ${ }^{d}$ and Makoto Ogawa*be
}

\begin{abstract}
Photoresponsive change in the basal spacing of cationic azo dye-layered silicate intercalation compounds was investigated using X-ray diffraction under controlled humidity conditions to investigate the mechanism of the photoresponse triggered by trans-cis photoisomerization. The molecular design of azo dyes was conducted and two cationic azo dyes (phenylazobenzene and phenylazonaphthalene) were used to obtain intercalation compounds with different packing and hydration. Whereas the trans-phenylazobenzene-layered silicate hardly adsorbed water vapor, the trans-phenylazonaphthalene intercalation compound strongly interacted with water. Both azo dyes photoisomerized in the interlayer space reversibly. Under the relative humidity of $95 \%$, the basal spacing of the phenylazobenzene-silicate increased upon UV irradiation, confirming that the change in the basal spacing was caused by the photoinduced hydration. Under the relative humidity of $6.8 \%$, the basal spacing of the phenylazonaphthalene-silicate decreased upon UV irradiation, suggesting that the packing of the phenylazonaphthalene in the interlayer space was changed to be compacted by the photochemical conversion to the cis-form.
\end{abstract}

\section{Introduction}

Stimuli-responsive supramolecular assemblies have been designed for creating smart materials. Reversible trans-to-cis photoisomerization of azobenzene by light irradiation or by thermal treatment changes its dipole moment as well as molecular geometry. This well-known stimuli-responsive phenomenon has been utilized as a trigger for the construction of photoresponsive materials. ${ }^{1}$ Azobenzene-containing supramolecular systems were synthesized to achieve photoresponse of guest binding. ${ }^{2}$ Azobenzene monolayer ${ }^{3}$ and multilayer ${ }^{4}$ deposited on substrates have been used to control the alignment of liquid crystals and polymers on the surface by

${ }^{a}$ Department of Chemistry and Materials Engineering, Shinshu University, 4-17-1 Wakasato, Nagano, Nagano 380-8553, Japan

${ }^{b}$ Department of Earth Sciences, Waseda University, 1-6-1 Nishiwaseda, Shinjuku, Tokyo 169-8050, Japan

${ }^{c}$ Center for Supramolecular Optoelectronic Materials, Seoul National University, 1 Gwanak-ro, Gwanak-gu, Seoul 151-744, Korea

${ }^{d}$ National Institute for Materials Science (NIMS), 1-1 Namiki, Tsukuba, Ibaraki 3050044, Japan

'Institute of Energy Science and Engineering, Vidyasirimedhi Institute of Science and Technology (VISTEC), 555 Moo 1 Tumbol Payupnai, Amphoe Wangchan, Rayong, 21210, Thailand. E-mail: makoto.ogawa@vistec.ac.th

$\dagger$ Electronic supplementary information (ESI) available: ${ }^{1} \mathrm{H},{ }^{13} \mathrm{C}$ NMR, and SPI-MS of AzNaph ${ }^{+}$; calculation of volume occupying azo dyes in the interlayer space and $\mathrm{XRD}$ patterns of trans- $\mathrm{AZ}^{+}$- and $\mathrm{AzNaph}^{+}$-magadiites recorded under different humidity (Fig. S1). See DOI: 10.1039/c6ra27749g irradiation. Controls of plasmonic resonance ${ }^{5 a}$ and achromatic polarization $^{5 b}$ are examples of applications of the command surfaces. The incorporation of azobenzene units into lowdimensional nanospaces (e.g., cylindrical pore of mesoporous silica $^{6}$ and 2D interlayer space ${ }^{7-12}$ ) has been investigated as supramolecular photoresponsive materials. Reversible changes in the basal spacing (interlayer expansion) of layered inorganic solids have been achieved after the careful design of the nanostructures. ${ }^{13,14}$ This is a photomechanical change in response to the change of the molecular configuration to the packing of molecular assemblies, ${ }^{\mathbf{1 3 , 1 4}}$ which cause the intercalation of additional molecular species. ${ }^{15}$ The molecular design of azo dyes ${ }^{13-16}$ and the molecular dynamics simulation ${ }^{17}$ indicated the importance of the functional groups attached to azobenzene in inducing the structural change.

We have been interested in the photochemistry of organic dyes intercalated in the interlayer space of layered silicates. ${ }^{7-9,11-13,15,16,18}$ Among available layered silicates, Na-magadiite (the ideal formula of $\left.\mathrm{Na}_{2} \mathrm{Si}_{14} \mathrm{O}_{29}\right)^{19}$ possesses following unique and useful properties for organizing cationic azo dyes; (1) the density of the cation exchange sites on the layer surface is

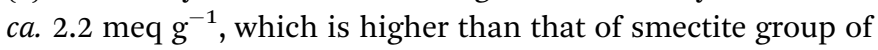
layered clay minerals; (2) it can conveniently be prepared in a laboratory by hydrothermal synthesis. We have reported the Xray diffraction (XRD)-detectable change in the basal spacing upon irradiation, for a cationic phenylazobenzene (Scheme 1a: abbreviated as $\mathrm{AZ}^{+}$) intercalated magadiite. ${ }^{13 b}$ The observed structural change of the intercalation compound by the 


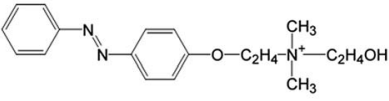

$\left(\mathrm{a}: \mathrm{AZ} \mathrm{Z}^{+}\right)$

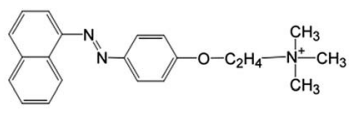

(b: $\mathrm{AzNaph}^{+}$)
Scheme 1 Molecular structures of (a) $\mathrm{AZ}^{+}$and (b) $\mathrm{AzNaph}^{+}$.

photoisomerization has been explained by the changes in the polarity, which accompany the adsorption of atmospheric water, and/or change in the packing of the intercalated $\mathrm{AZ}^{+}$. In order to understand the mechanisms of the photoinduced structural change as well as to apply the phenomena, more systematic investigation is worth conducting. In this study, a cationic phenylazonaphthalene (Scheme 1b: AzNaph ${ }^{+}$) was synthesized and intercalated in the interlayer space of $\mathrm{Na}-$ magadiite in the expectation of causing differences in the packing and the photoinduced hydration.

\section{Experimental section}

\section{Preparation of the cationic azo dyes}

$\mathrm{AZ}^{+}-\mathrm{Br}^{-}, \quad p$-[2-(2-hydroxyethyldimethylammonioethoxy)phenylazo]benzene bromide, was prepared by the reaction of phenylazophenol with dibromoethane and subsequent reaction with dimethylaminoethanol. The dye was used after recrystallization from ethanol and characterized by ${ }^{1} \mathrm{H}$ NMR and $\mathrm{CHN}$ analysis (calculated for $\mathrm{C}_{18} \mathrm{H}_{24} \mathrm{~N}_{3} \mathrm{O}_{2} \mathrm{Br}$ : C, 54.8; $\mathrm{H}, 6.13 ; \mathrm{N}, 10.7$; found $\mathrm{C}$, 53.7; H, 5.97; N, 10.3 mass\%) and mass spectrometry. ${ }^{13 b}$

$\mathrm{AzNaph}^{+}-\mathrm{Br}^{-}, \quad$ 1-[(4-trimethylammonioethoxy)phenylazo] naphthalene bromide, was synthesized by the reaction between phenylazonaphthalene and dibromoethane, followed by the quaternization reaction using trimethylamine. The product was used after recrystallization from ethanol and analyzed by ${ }^{1} \mathrm{H}$ and ${ }^{13} \mathrm{C}$ NMR analysis and mass spectrometry (the results are summarized in ESI $\dagger$ ).

\section{Intercalation of the cationic azo dyes into Na-magadiite}

Na-magadiite was prepared by a hydrothermal reaction as reported previously. ${ }^{19 a}$ Intercalation of cationic azo dyes $\left(\mathrm{AzNaph}^{+}\right.$ and $\mathrm{AZ}^{+}$) into $\mathrm{Na}$-magadiite was conducted by the conventional ion-exchange reactions. Na-magadiite was mixed with an aqueous solution of the cationic azo dye $(2.0 \mathrm{mM})$ at a molar ratio of $\mathrm{Na}: \mathrm{AzNaph}^{+}=1: 1.7$ or $\mathrm{Na}: \mathrm{AZ}^{+}=1: 1.2$. The mixture was allowed to react for $24 \mathrm{~h}$ at $343 \mathrm{~K}$. After centrifugation, the resulting solid was washed with acetone, followed by being dried under a reduced pressure at room temperature. In order to record UV-vis absorption spectra, a supported film on a quartz substrate was prepared by embedding the mixture of the azo dye-magadiite with a chloroform solution of poly(methyl methacrylate) (PMMA).

\section{Photochemical reactions}

The photochemical reactions of the intercalated azo dyes were conducted using UV and visible light irradiation with a Hamamatsu Photonics $150 \mathrm{~W}$ high pressure $\mathrm{Hg}$-Xe lamp. For the trans-to-cis reactions of $\mathrm{AZ}^{+}$and $\mathrm{AzNaph}^{+}$, band-pass filters, HOYA U-340 and HOYA B390 (the transmittance centered at 350 and $405 \mathrm{~nm}$ ), were used for isolating UV light, respectively. For the cis-to-trans backward reactions, sharp-cut filters, HOYA L42 (cut-off wavelength is $420 \mathrm{~nm}$ ) and HOYA Y52 (cut-off wavelength is $520 \mathrm{~nm}$ ) were used to irradiate visible light toward $\mathrm{AZ}^{+}$ and $\mathrm{AzNaph}^{+}$, respectively.

\section{Characterization}

Adsorption-desorption isotherms of water from vapor phase were obtained using a BELSORP-max adsorption equipment (Microtrack BEL Co. Ltd.). Before the experiment, the AzNaph ${ }^{+}$ magadiite powder was dried at $333 \mathrm{~K}$. XRD patterns were recorded on a RIGAKU 2100s humidity-controlled equipment using monochromatic $\mathrm{Cu} \mathrm{K} \alpha$ radiation, operated at $20 \mathrm{~mA}$ and $40 \mathrm{kV}$. UV-visible absorption spectra were recorded on a Shimadzu UV 3100 PC spectrophotometer. The composition of the azo dye-intercalated magadiite was determined by $\mathrm{CHN}$ analysis (Perkin Elmer 2400 II instrument).

\section{Results and discussion}

As shown in XRD patterns (Fig. 1a), the basal spacing of $\mathrm{Na}-$ magadiite $(1.57 \mathrm{~nm})$ increased to 3.01 and $2.74 \mathrm{~nm}$ for $\mathrm{AzNaph}^{+}$and $\mathrm{AZ}^{+}$-magadiites, respectively, where the interlayer expansion (the gallery height) was derived by subtracting the thickness of the silicate layer of magadiite $(1.12 \mathrm{~nm})^{20}$ to be 1.89 and $1.62 \mathrm{~nm}$. Considering the interlayer expansion and the molecular size (1.9 $\mathrm{nm}$ for the long axis of each azo cation), interdigitated monolayer or bilayer coverage is possible orientation of the interlayer azo dyes (Fig. 1b). The amount of $\mathrm{AzNaph}^{+}$in the product was determined by $\mathrm{CHN}$ analysis (C, 16.0\%; $\mathrm{N}$, $2.2 \%$ ) to be $0.85 \mathrm{~mol} / \mathrm{Si}_{14} \mathrm{O}_{29}$, which was smaller than that $(1.8$ $\mathrm{mol} / \mathrm{Si}_{14} \mathrm{O}_{29}$ from C, $25.7 \%$;, $\left.3.6 \%\right)^{13 b}$ of $\mathrm{AZ}^{+}$. On the bases of the differences in the interlayer expansion, the adsorbed amount of azo dye, and the molecular size, there seems to be more space (lower packing density) to rotate naphthalene group in $\mathrm{AzNaph}^{+}$in the interlayer space (calculation in detail has been described in ESI $\dagger$ ).

The adsorption/desorption isotherms of water vapor (298 K) on the trans-forms are shown in Fig. 2. Whereas $\mathrm{AZ}^{+}$-magadiite hardly adsorbed water vapor, $\mathrm{AzNaph}^{+}$-magadiite was shown to have a larger water adsorption capacity. The basal spacing of $\mathrm{AzNaph}^{+}$-magadiite was recorded using a humidity-controlled XRD equipment. The value was $3.08 \mathrm{~nm}$ under the $\mathrm{RH}$ of $90 \%$, which is larger than that $(2.89 \mathrm{~nm})$ observed for the sample under the $\mathrm{RH}$ of $10 \%$, indicating that the interlayer space of $\mathrm{AzNaph}^{+}$-magadiite is expandable by the water adsorption (the XRD patterns are shown in ESI, Fig. S1†). The basal spacing of trans-AZ ${ }^{+}$-magadiite $(2.74 \mathrm{~nm})$ was not sensitive for the humidity (Fig. S1 $\dagger$ ). In AzNaph ${ }^{+}$-magadiite, residual $\mathrm{Na}$ ions ( $c a .1 .1 \mathrm{~mol} / \mathrm{Si}_{14} \mathrm{O}_{29}$ ) and interlayer silanol groups are possible adsorption sites for water vapor. In addition, packing of the dyes in the interlayer space (loosely packed $\mathrm{AzNaph}^{+}$and densely packed $\mathrm{AZ}^{+}$) is thought to be concerned for the adsorptive characteristics of the intercalation compounds. 
(a)

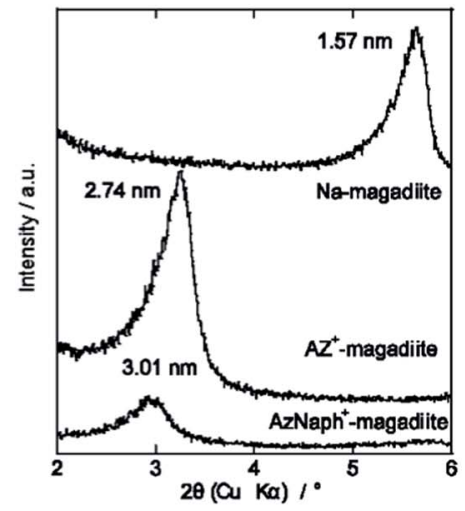

(b)

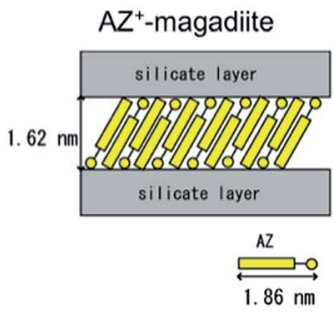

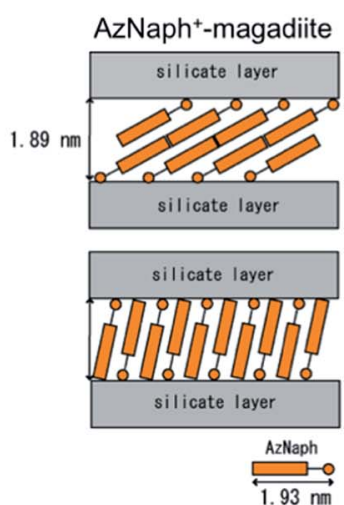

Fig. 1 (a) XRD patterns of $\mathrm{Na}$-magadiite, $\mathrm{AZ}^{+}$-magadiite, and $\mathrm{AzNaph}{ }^{+}$-magadiite recorded under ambient atmosphere, (b) schematic drawing of the interlayer structures of $\mathrm{AzNaph}^{+}$- and $\mathrm{AZ} \mathrm{Z}^{+}$-magadiite.

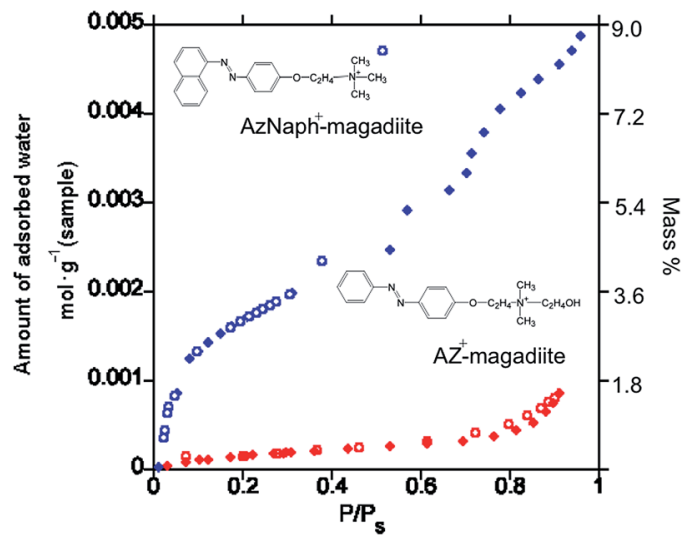

Fig. 2 Adsorption (filled symbols)/desorption (open symbols) isotherms of water vapor (298 K) on $\mathrm{AzNaph}^{+}$- (red) and $\mathrm{AZ}^{+}$-magadiite (blue) intercalation compounds.

UV irradiation led the change in the absorption spectrum of the AzNaph ${ }^{+}$-magadiite as shown in Fig. 3; absorbance of the band ascribed to the trans-isomer (at around $390 \mathrm{~nm}$ ) decreased

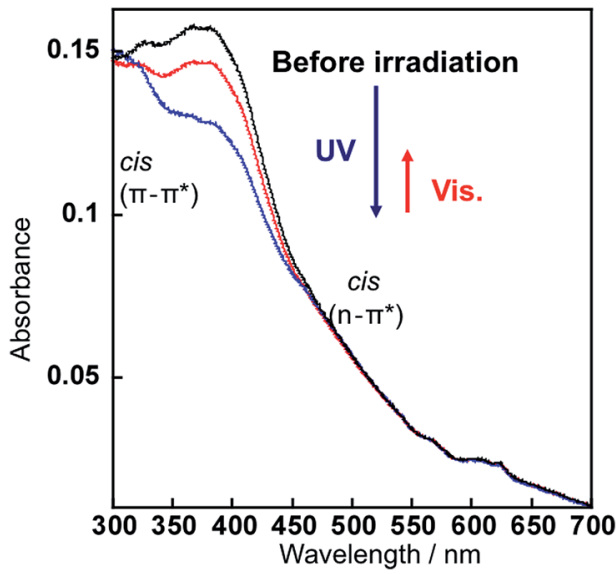

Fig. 3 The absorption spectra of $\mathrm{AzNaph}^{+}$-magadiite embedded in PMMA: before (black), after UV irradiation (blue) for $10 \mathrm{~min}$, and subsequent visible light irradiation (red) for $10 \mathrm{~min}$. after the UV irradiation, indicating the trans-to-cis photoisomerization of the interlayer $\mathrm{AzNaph}^{+}$. The absorption spectrum was regenerated upon visible light irradiation, suggesting that the photochemically formed cis-AzNaph ${ }^{+}$photoisomerized to trans-form. The absorbance of the cis-isomer (at around 500 $\mathrm{nm}$ ) is quite small due to the $\mathrm{n}-\pi *$ forbidden transition. Based on the change in the absorbance of the trans-isomer, the fraction of the photochemically formed cis-isomer was estimated to be $14 \%$ at the photostationary state. ${ }^{21}$ Similar spectral change in responses to UV and visible light irradiations was observed in the $\mathrm{AZ}^{+}$-magadiite system, and the fraction of the cis-isomer was up-to $45 \% .^{13 b}$

Photoinduced change in the basal spacing of $\mathrm{AZ}^{+}$-magadiite was observed when photoirradiation was conducted under a high humidity condition ( $\mathrm{RH}=95 \%$ ) (Fig. 4); the basal spacing increased from 2.73 to $2.76 \mathrm{~nm}$ upon UV irradiation. It was explained that, due to the polar nature of $c i s-\mathrm{AZ}^{+}$, the adsorption of atmospheric water to the photochemically formed cis- $\mathrm{AZ}^{+}$-magadiite occurred to cause the expansion of the interlayer space. In contrast, the basal spacing of $\mathrm{AzNaph}^{+}-$ magadiite decreased from 2.89 to $2.79 \mathrm{~nm}$ when UV irradiation was conducted under a dry $\mathrm{N}_{2}$ atmosphere $(\mathrm{RH}=6.8 \%)$ (Fig. 5$)$. (a) Under humidity of $5 \%$

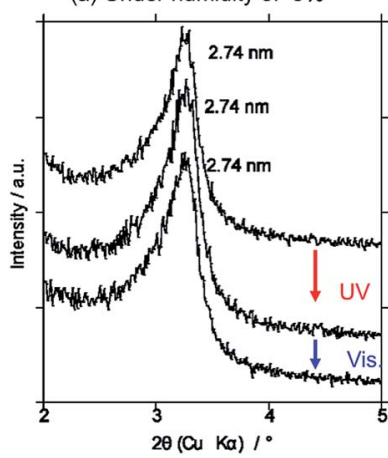

(b) Under humidity of $\mathbf{9 5 \%}$

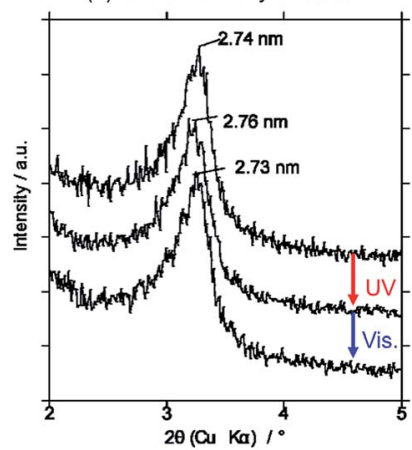

Fig. 4 Change in the XRD pattern of trans-AZ ${ }^{+}$-magadiite upon UV and visible light irradiations at different humidity of (a) $\mathrm{RH}=5$ and (b) $\mathrm{RH}=95$ for 10 min each. 


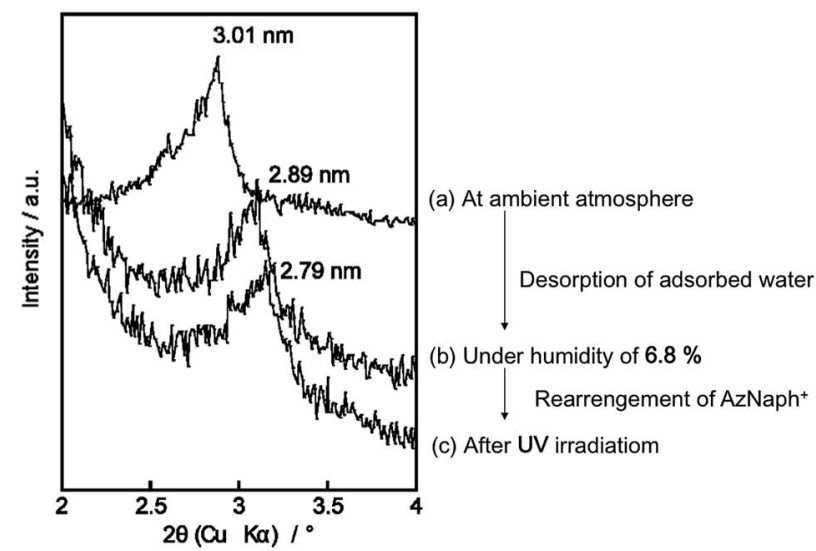

Fig. 5 XRD patterns of $\mathrm{AzNaph}^{+}$-magadiite recorded under (a) ambient atmosphere, (b) $\mathrm{RH}$ of $6.8 \%$ at ground state and (c) UV irradiation for $10 \min (\mathrm{RH}=6.8 \%)$.

The cis-isomer co-existed with the trans-isomer in the same interlayer space as suggested by the single phase-XRD patterns before and during the irradiation. Geometrical change from trans to cis-AzNaph ${ }^{+}$triggered the rearrangement of the overall guest packing in the interlayer space, which was thought to affect the decreased basal spacing upon UV irradiation. It is clear from a molecular simulation (Scheme 2) that a larger exclusion volume of the substituent bonded to azo group is required for $\mathrm{AzNaph}^{+}$to photoisomerize. Once the basal spacing decreased, the value did not return to that before UV irradiation probably due to the slow recovery of a portion of the photochemically formed cis-form. Careful examination of the irradiation conditions will be required to understand the structural changes.

We recorded the XRD patterns and the absorption spectra after reaching photo-stationary state $(10 \mathrm{~min})$. Time for structural transition (basal spacing change) was strongly affected whether accompanying intercalation of a molecule by light irradiation or not. When the photoinduced intercalation was not involved, the changes in absorption spectrum and basal spacing occurred simultaneously. ${ }^{14 c}$ On the other hand, a longer time than the spectral change was required to the transition

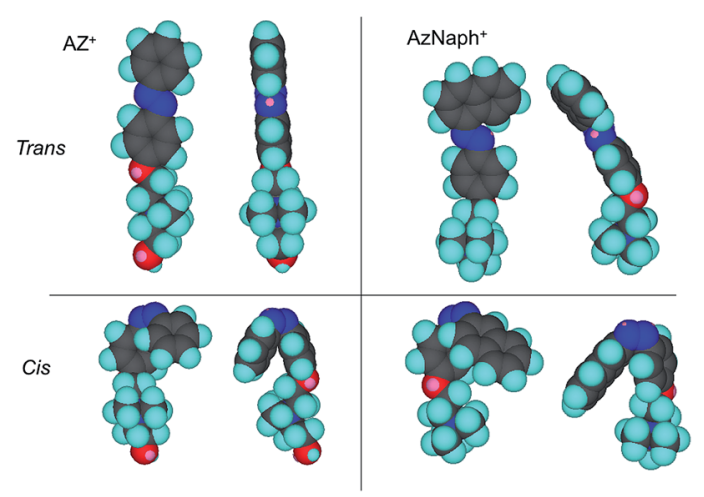

Scheme 2 Molecular simulation structures of trans- and cis-forms for $\mathrm{AZ}^{+}$- and $\mathrm{AzNaph}^{+}$. because the intercalation of a molecule (phenol) was a rate determining step to reach the steady state. ${ }^{15 b}$ In the present AzNaph $^{+}$-magadiite system, simultaneous transition with the trans-to-cis isomerization is plausible because of the effect of the water intercalation.

\section{Conclusions}

The structural changes of the cationic azo dye-magadiite intercalation compounds upon irradiation have been investigated under controlled humidity conditions. Two azo dyes (azobenzene and azonaphthalene) gave photoinduced structural changes from different mechanisms. Hydration of the photochemically formed cis-form of the cationic azobenzene-magadiite was the reason of the increase in the basal spacing by the UV irradiation. The change in the basal spacing of the cationic azonaphthalene-magadiite intercalation compound was observed by the irradiation under the dry condition (decrease by UV irradiation), which was thought to cause by the change in the packing of the azonaphthalene in the interlayer space of magadiite. The observed photoinduced structural changes based on different mechanisms reminded the importance of the mechanisms on the applications of the stimuli responsive supramolecular systems under different operating conditions.

\section{Notes and references}

1 Photochromism: Molecules and Systems, ed. H. Dürr and H. Bouas-Laurent, Elsevier, Amsterdam, 2003.

2 (a) G. S. Kumar and D. C. Neckers, Chem. Rev., 1989, 89, 1915; (b) J. Anzai and T. Osa, Tetrahedron, 1994, 50, 4039; (c) I. Wilier, Acc. Chem. Res., 1997, 30, 347; (d) K. Hoffmann, F. Marlow and J. Caro, Adv. Mater., 1997, 9, 567; (e) J. Park, D. Yuan, K. T. Pham, J.-R. Li, A. Yakovenko and H.-C. Zhou, J. Am. Chem. Soc., 2012, 134, 99; (f) N. Yanai, T. Uemura, M. Inoue, R. Matsuda, T. Fukushima, M. Tsujimoto, S. Isoda and S. Kitagawa, J. Am. Chem. Soc., 2012, 134, 4501; $(g)$ A. Harada, Y. Takashima and M. Nakahata, Acc. Chem. Res., 2014, 47, 2128; (h) New Frontiers in Photochromism, ed. M. Irie, Y. Yokoyama and T. Seki, Springer, Japan, 2013; (i) T. H. Tran-Thi, R. Dagnelie, S. Crunaire and L. Nicole, Chem. Soc. Rev., 2011, 40, 621; (j) B. Lebeau and P. Innocenzi, Chem. Soc. Rev., 2011, 40, 886; (k) D.-H. Qu, Q.-C. Wang, Q.-W. Zhang, X. Ma and H. Tian, Chem. Rev., 2015, 115, 7543.

3 (a) K. Ichimura, Y. Suzuki, T. Seki, A. Hosoki and K. Aoki, Langmuir, 1988, 4, 1214; (b) K. Ichimura, Chem. Rev., 2000, 100, 1847.

4 (a) T. Seki, S. Nagano and M. Hara, Polymer, 2013, 54, 6053; (b) T. Nakai, D. Tanaka, M. Hara, S. Nagano and T. Seki, Langmuir, 2016, 32, 909.

5 (a) L. D. Sio, G. Kjein, S. Serak, N. Tabiryan, A. Cunningham, C. M. Tone, F. Ciuchi, T. Bürgi, C. Umeton and T. Bunning, J. Mater. Chem. C, 2013, 1, 7483; (b) C. Oh and M. J. Escuti, Opt. Lett., 2008, 33, 2287.

6 (a) M. Ogawa, J. Photochem. Photobiol., C, 2002, 3, 129; (b) M. Sohmiya, K. Saito and M. Ogawa, Sci. Technol. Adv. 
Mater., 2015, 16, 054201; (c) N. Mizoshita, T. Tani and S. Inagaki, Chem. Soc. Rev., 2011, 40, 789; (d) A. Stein, B. J. Melde and R. C. Schroden, Adv. Mater., 2000, 12, 1403.

7 T. Okada, M. Sohmiya and M. Ogawa, Photochromic Intercalation Compounds in Photofunctional Layered Materials, ed. D. Yan and M. Wei, Springer Int. Pub., Switzerland, 2015, pp. 177-211.

8 (a) M. Ogawa and K. Kuroda, Chem. Rev., 1995, 95, 399; (b) Comprehensive Supramolecular Chemistry, ed. G. Alberti and T. Bein, Pergamon, Oxford, 1996, vol. 7; (c) K. Takagi and T. Shichi, Photophysics and Photochemistry in Clay Materials in Solid State and Surface Photochemistry, ed. V. Ramamurthy and K. S. Schanze, Marcel Dekker, New York, 2000, pp. 31-110; (d) S. Takagi, T. Shimada, Y. Ishida, T. Fujimura, D. Masui, H. Tachibana, M. Eguchi and H. Inoue, Langmuir, 2013, 29, 2108.

9 (a) M. Ogawa, H. Kimura, K. Kuroda and C. Kato, Clay Sci., 1996, 10, 57; (b) M. Ogawa, M. Hama and K. Kuroda, Clay Miner., 1999, 34, 213; (c) M. Sasaki and T. Fukuhara, Photochem. Photobiol., 1997, 66, 716; (d) H. Kandori, T. Ichioka and M. Sasaki, Chem. Phys. Lett., 2002, 354, 251. 10 W. Fujita and K. Awaga, J. Am. Chem. Soc., 1997, 119, 4563. 11 (a) T. Yamamoto, Y. Umemura, O. Sato and Y. Einaga, Chem. Mater., 2004, 16, 1195; (b) T. Yamamoto, N. Saso, Y. Umemura and Y. Einaga, J. Am. Chem. Soc., 2009, 131, 13196.

12 T. Umemoto, Y. Ohtani, T. Tsukamoto, T. Shimada and S. Takagi, Chem. Commun., 2014, 50, 314.

13 (a) M. Ogawa, K. Fujii, K. Kuroda and C. Kato, Mater. Res. Soc. Symp. Proc., 1991, 233, 89; (b) M. Ogawa, T. Ishii, N. Miyamoto and K. Kuroda, Adv. Mater., 2001, 13, 1107; (c) T. Fujita, N. Iyi and Z. Klapyta, Mater. Res. Bull., 1998, 33, 1693; (d) N. Iyi, T. Fujita, C. V. Yelamaggad and F. L. Arbeloa, Appl. Clay Sci., 2001, 19, 47; (e) S. Guo, K. Matsukawa, T. Miyata, T. Okubo, K. Kuroda and A. Shimojima, J. Am. Chem. Soc., 2015, 137, 15434.

14 (a) Z. W. Tong, S. Takagi, T. Shimada and H. Tachibana and Inoue, J. Am. Chem. Soc., 2006, 128, 684; (b) Z. W. Tong, S. Sasamoto, T. Shimada, S. Takagi, H. Tachibana,
X. B. Zhang, D. A. Tryk and H. Inoue, J. Mater. Chem., 2008, 18, 4641; (c) Y. Nabetani, H. Takamura, Y. Hayasaka, S. Sasamoto, Y. Tanamura, T. Shimada, D. Masui, S. Takagi, H. Tachibana, Z. Tong and H. Inoue, Nanoscale, 2013, 5, 3182; (d) Y. Nabetani, H. Takamura, Y. Hayasaka, T. Shimada, S. Takagi, H. Tachibana, D. Masui, Z. Tong and H. Inoue, J. Am. Chem. Soc., 2011, 133, 17130; (e) J. Han, D. Yan, W. Shi, J. Ma, H. Yan, M. Wei, D. G. Evans and X. Duan, J. Phys. Chem. B, 2010, 114, 5678.

15 (a) T. Okada, Y. Watanabe and M. Ogawa, Chem. Commun., 2004, 320; (b) T. Okada, Y. Watanabe and M. Ogawa, $J$. Mater. Chem., 2005, 15, 987; (c) T. Okada, H. Sakai and M. Ogawa, Appl. Clay Sci., 2008, 40, 187.

16 (a) M. Ogawa, Chem. Mater., 1996, 8, 1347; (b) M. Ogawa and A. Ishikawa, J. Mater. Chem., 1998, 8, 463; (c) M. Ogawa, J. Mater. Chem., 2002, 12, 3304; (d) J. Bujdak, N. Iyi and T. Fujita, J. Colloid Interface Sci., 2003, 262, 282; (e) S. Guo, W. Chaikittisilp, T. Okubo and A. Shimojima, RSC Adv., 2014, 4, 25319.

17 (a) H. Heinz, R. A. Vaia, H. Koerner and B. L. Farmer, Chem. Mater., 2008, 20, 6444; (b) H. Heinz, Clay Miner., 2012, 47, 205.

18 M. Ogawa, M. Yamamoto and K. Kuroda, Clay Miner., 2001, 36, 263.

19 (a) K. Kosuge, A. Yamazaki, A. Tsunashima and R. Otsuka, J. Ceram. Soc. Jpn., 1992, 100, 326; (b) G. Lagaly, Adv. Colloid Interface Sci., 1979, 11, 105; (c) G. Lagaly, K. Beneke and A. Weiss, Am. Mineral., 1975, 60, 642; (d) G. W. Brindley, Am. Mineral., 1969, 54, 1583; (e) H. P. Eugster, Science, 1967, 157, 1177.

20 J. M. Rojo, E. Ruiz-Hitzky and J. Sanz, Inorg. Chem., 1988, 27, 2785.

21 The absorption spectra of the film are different from that of solution, because of the light scattering by small particles of the azo dye-magadiite. In order to subtract the scattering effects, the baseline was normalized from the original spectrum before measuring the absorbance of the transisomer. 